\title{
Giant thrombus in ascending aorta and aortic arch
}

\author{
Lukasz Jaworski, MD, PhD, ${ }^{a}$ Marcin Fijalkowski, MD, PhD, ${ }^{\text {b }}$ and Jan Rogowski, MD, $\mathrm{PhD}^{\mathrm{a}}$
}
From the Department of Cardiosurgery ${ }^{\mathrm{a}}$ and the First Department of Cardiology, ${ }^{\mathrm{b}}$ Medical University of Gdansk, Gdansk, Poland.
Disclosures: Authors have nothing to disclose with regard to commercial support. Received for publication Dec 22, 2012; accepted for publication Jan 11, 2013; available ahead of print Feb 15, 2013.
Address for reprints: Marcin Fijalkowski, MD, PhD, First Department of Cardiology, Medical University of Gdansk, Debinki 7, 80-291 Gdansk, Poland (E-mail: mfijalkowski@gumed.edu.pl).
J Thorac Cardiovasc Surg 2013;145:1668-9
$0022-5223 / \$ 36.00$
Copyright (C) 2013 by The American Association for Thoracic Surgery
http://dx.doi.org/10.1016/j.jtcvs.2013.01.009

We report the case of a 65-year-old man with arterial hypertension and diabetes mellitus who was admitted with symptoms of left upper limb acute ischemia. Rescue left brachial artery embolectomy was performed. Subsequently obtained 64-slice computed tomographic angiography revealed pedunculated formation of thrombus $70 \times 25 \mathrm{~mm}$ in diameter (Figure 1,A) attached to the distal part of the ascending aorta (Figure 1, B; Videos 1 and 2 ). There were no signs of significant atherosclerotic process, wall dissection, trauma, or malignancy of ascending aorta and aortic arch.

Urgent surgery was performed. After deep hypothermic and circulatory arrest, longitudinal aortotomy revealed thrombus material, $80 \times 30 \mathrm{~mm}$ in diameter and characterized by an irregular distal edge

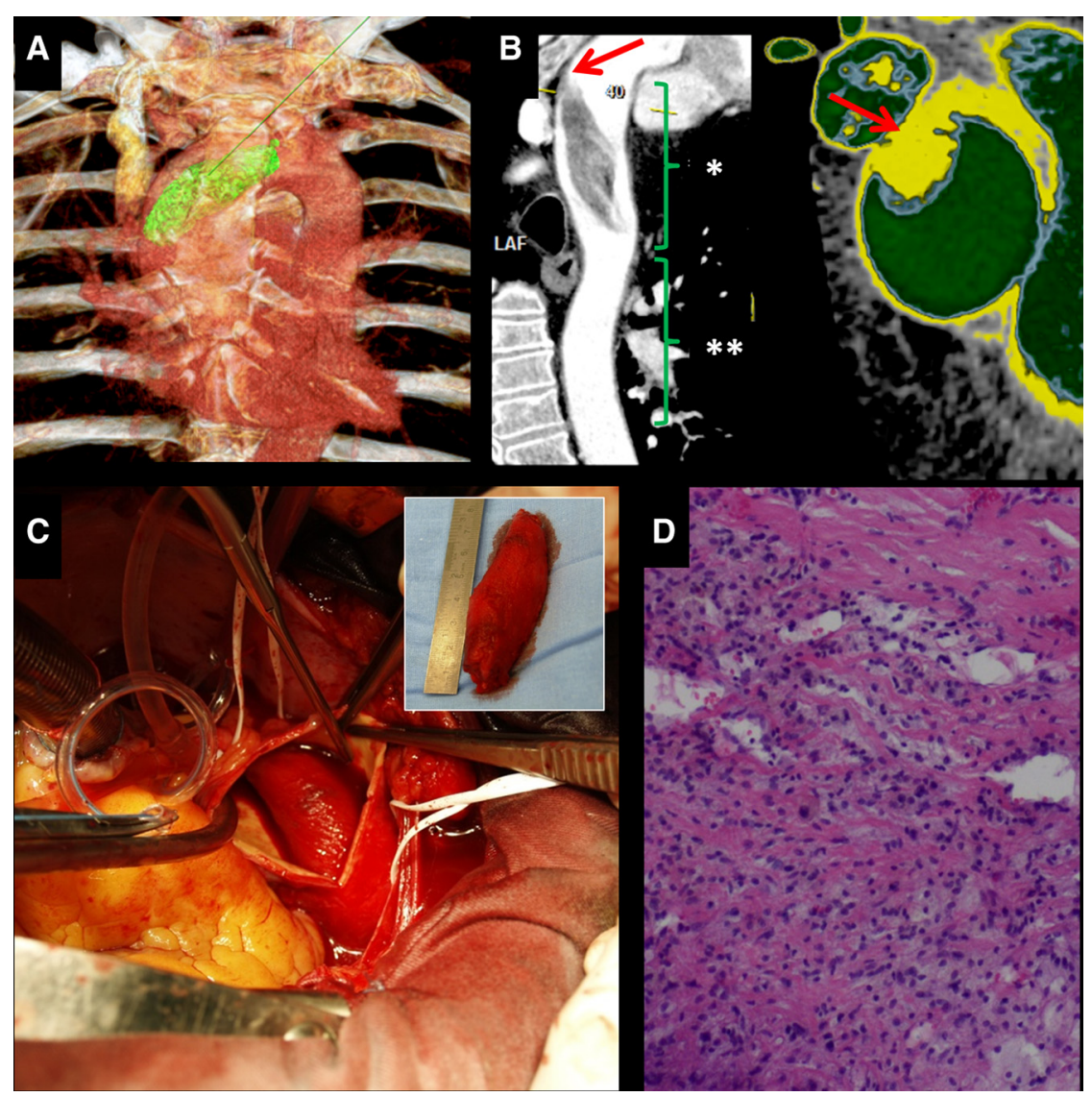

FIGURE 1. A, Pedunculated formation of thrombus $70 \times 25 \mathrm{~mm}$ in diameter can be seen on 64-slice computed tomographic angiography. B, Thrombus attachment to the distal part of the ascending aorta can be seen on 64-slice computed tomographic angiography. Red arrows show the attachment of the thrombus to the wall of the aorta; asterisk denotes aortic arch; double asterisk denotes descending aorta. C, Intraoperative photograph and surgical specimen (inset). Thrombus is $80 \times 30 \mathrm{~mm}$ in diameter and characterized by an irregular distal edge. D, On histologic examination, infiltrating macrophages can be seen transforming into foam cells. 
(Figure 1,C). Aortic thrombus originated from the distal part of the ascending aorta, with no macroscopic signs of atherosclerosis or intramural hematoma. The part of aortic wall with thrombus attachment was subsequently removed and replaced with a vascular prosthesis. At histologic examination, an early stage of atherosclerosis was confirmed, with infiltrating macrophages transforming into foam cells (Figure 1,D). The patient had no coagulation disorder. Recovery was uneventful, and there was no recurrence of aortic thrombus within 3 months of observation.

Although an ascending aortic thrombus is a very rare finding, it may cause major embolic complications. This case demonstrates that spontaneous thrombus formation can be identified in high-flow vascular regions. It also demonstrates that even early-stage atheromatous changes causing endothelial dysfunction in the aorta may be potentially life threatening. 